\title{
DNA methyltransferase isoforms expression in the temporal lobe of epilepsy patients with a history of febrile seizures
}

\author{
Laurence de Nijs ${ }^{1,2^{*}}$ (D), Kyonghwan Choe ${ }^{1}$, Hellen Steinbusch ${ }^{1}$, Olaf E. M. G. Schijns ${ }^{1,4,5}$, Jim Dings ${ }^{1,4,5}$,
} Daniel L. A. van den Hove ${ }^{1,3}$, Bart P. F. Rutten ${ }^{1 \dagger}$ and Govert Hoogland ${ }^{1,4,5+}$

\begin{abstract}
Background: Temporal lobe epilepsy (TLE) with hippocampal sclerosis (HS) is a common pharmaco-resistant epilepsy referred for adult epilepsy surgery. Though associated with prolonged febrile seizures (FS) in childhood, the neurobiological basis for this relationship is not fully understood and currently no preventive or curative therapies are available. DNA methylation, an epigenetic mechanism catalyzed by DNA methyltransferases (DNMTs), potentially plays a pivotal role in epileptogenesis associated with FS. In an attempt to start exploring this notion, the present cross-sectional pilot study investigated whether global DNA methylation levels (5-mC and 5-hmC markers) and DNMT isoforms (DNMT1, DNMT3a1, and DNMT3a2) expression would be different in hippocampal and neocortical tissues between controls and TLE patients with or without a history of FS.
\end{abstract}

Results: We found that global DNA methylation levels and DNMT3a2 isoform expression were lower in the hippocampus for all TLE groups when compared to control patients, with a more significant decrease amongst the TLE groups with a history of FS. Interestingly, we showed that DNMT3a1 expression was severely diminished in the hippocampus of TLE patients with a history of FS in comparison with control and other TLE groups. In the neocortex, we found a higher expression of DNMT1 and DNMT3a1 as well as increased levels of global DNA methylation for all TLE patients compared to controls.

Conclusion: Together, the findings of this descriptive cross-sectional pilot study demonstrated brain region-specific changes in DNMT1 and DNMT3a isoform expression as well as global DNA methylation levels in human TLE with or without a history of FS. They highlighted a specific implication of DNMT3a isoforms in TLE after FS. Therefore, longitudinal studies that aim at targeting DNMT3a isoforms to evaluate the potential causal relationship between FS and TLE or treatment of FS-induced epileptogenesis seem warranted.

Keywords: Febrile seizures, Temporal lobe epilepsy, Epigenetics, DNA methylation, DNA methyltransferases

\section{Introduction}

Temporal lobe epilepsy (TLE) is the most common type of focal epilepsy in adulthood. TLE is drug-resistant in about one third of patients, necessitating surgical resection of the epileptogenic focus as a curative treatment

\footnotetext{
* Correspondence: laurence.denijs@maastrichtuniversity.nl

${ }^{\dagger}$ Bart P.F. Rutten and Govert Hoogland contributed equally to this work. ${ }^{1}$ School for Mental Health and Neuroscience (MHeNS), Department of Psychiatry and Neuropsychology, Faculty of Health, Medicine and Life Sciences, Maastricht University, Universiteitssingel 50, 6229, ER, Maastricht, The Netherlands

${ }^{2}$ GIGA-Neurosciences, University of Liège, Liège, Belgium

Full list of author information is available at the end of the article
}

option [1]. Drug-resistant TLE is frequently associated with hippocampal sclerosis (HS) as the major pathological entity. In general, HS is histopathologically characterized by astrogliosis and neuronal loss, most prominently in the cornu ammonis (CA) 1 and CA3 regions and in the dentate gyrus (DG) of the hippocampus. In addition, $50 \%$ of the patients with $\mathrm{HS}$ display various degrees of granule cell dispersion in the DG [2]. Typical febrile seizures (FS) are fever-triggered convulsions, affecting $2-14 \%$ of children between the age of 6 months and 5 years. FS have been linked to the development of subsequent TLE with HS in $30-40 \%$ of the cases [3].

(c) The Author(s). 2019 Open Access This article is distributed under the terms of the Creative Commons Attribution 4.0 International License (http://creativecommons.org/licenses/by/4.0/), which permits unrestricted use, distribution, and 
Little is known about the pathophysiological mechanisms of TLE, especially after FS. In a well-characterized rodent model of FS, i.e., that of neonatal hyperthermia, FS have been shown to result in enhanced hippocampal excitability and consequently an increase in epileptic seizures [4]. Molecular and cellular changes have been demonstrated and correlated to the generation of this enhanced excitability (for review, see [5]). Identifying the mechanisms that regulate the transcription of genes that mediate these alterations may open new perspectives for the treatment of drug-resistant epilepsy or for the prevention of FS-induced epileptogenesis.

Epigenetic mechanisms, which refer to inherited and acquired changes in gene transcription that occurred without modification in the DNA sequence, have been proposed to play a prominent role in various neurological disorders, including epilepsy [6]. They are involved in multiple aspects of brain functions and associated behaviors, e.g., impacting on neuronal development, neuronal and synaptic plasticity, and memory [7]. DNA methylation, a key epigenetic modification implicated in the regulation of gene transcription, has been shown to be highly dynamic in the adult brain, e.g., in the hippocampus in response to neural activity [8], and it is thought to be crucial for brain homeostasis. DNA methylation is the covalent modification of cytosine residues on CpG dinucleotides to form 5-methylcytosine $(5-\mathrm{mC})$ that is catalyzed by DNA methyltransferases (DNMTs) [9]. 5Hydroxymethylcytosine $(5-\mathrm{hmC})$ is the oxidative variant of $5-\mathrm{mC}$ and is generated during a reaction catalyzed by ten-eleven translocation enzymes [10]. The exact function of $5-\mathrm{hmC}$ is still not fully elucidated, but evidence indicates that 5 -hmC marks can regulate gene expression by driving DNA demethylation [11]. Moreover, 5 -hmC has been shown to be highly abundant in the brain compared to other tissues [12].

Various types of DNMTs have been reported including DNMT1, DNMT3a, and DNMT3b. DNMT1, referred to as maintenance DNMT, conserves DNA methylation after every cellular DNA replication cycle, whereas DNMT3a and DNMT3b promote de novo DNA methylation. While more than 30 enzymatically active isoforms of DNMT3b exist [13], two isoforms of DNMT1 [14] and DNMT3a [15] have been described. For DNMT3a, these include the full-length isoform, known as DNMT3a1, and the shorter one, called DNMT3a2. DNMT3a2 lacks the 219 amino acids at the N-terminal part of DNMT3a1 and is transcribed from an alternative promoter in the sixth intron of the DNMT3a gene [15].

DNMTs have been shown to play an important role during brain development as inactivation of Dnmt1 in mouse leads to embryonic lethality [16] and DMNT3a/ 3b knockout mice die within few weeks postnatally [17]. The high expression of DNMT1, DNMT3a2, and DNMT3b in early stages of neurogenesis $[15,18,19]$ decreases upon differentiation, while DNMT3a1 protein levels increase postnatally $[19,20]$. Over the lifespan, the abundance of DNMT3a1 declines following synaptogenesis in neurons with very low levels during aging [19]. Remarkably, all the DNMT isoforms are still expressed in adult brain with DNMT1 and DNMT3a1 being more abundant than DNMT3b and DNMT3a2 $[15,18,21$, 22]. DNMT proteins were reported to be strongly expressed in neuronal as compared to glial cells [23].

In addition to their role during development, studies have demonstrated the functional importance of DNMTs and dynamic methylation in the adult brain, e.g., in learning and memory, synaptic plasticity, and behavior [24-28]. Recent evidences suggest that aberrant DNA methylation and expression of DNMTs may be causal or contributing factors in a variety of neurological disorders including epilepsies [26]. For example, preclinical data have shown altered DNA methylation patterns and DNMT activity in rodent models of status epilepticus and chronic TLE [29-31] as well as in human TLE [32-34]. In addition, the expression of DNMT1 and DNMT3a was shown to be increased in the neocortex of TLE patients [35].

Based on these findings, one could speculate that DNA methylation represents a crucial event triggered by FS, which leaves a permanent imprint on gene expression and physiological processes, thereby mediating epileptogenesis responsible for the development of TLE later in life. In order to start exploring this notion at a descriptive level, the present pilot study aimed to assess the expression of DNMT1 and DNMT3a isoforms and the level of global DNA (hydroxy)methylation in the pathogenesis of FS followed by TLE. We thereby tested the hypothesis that hippocampal and neocortical expression of DNMT1 and DNMT3a isoforms, as well as the levels of markers of global DNA methylation and hydroxymethylation (5-mC and 5-hmC, respectively), would be different between controls and TLE patients with or without a history of FS.

\section{Results \\ Expression of DNMT1 in the neocortex and hippocampus of TLE patients}

We first analyzed the expression levels of the two DNMT1 protein isoforms by Western blot using tissue from the hippocampus (Fig. 1a) and temporal neocortex (Fig. 1c) of controls (CTRL) and three TLE patient groups $\left(\mathrm{HS}^{-}, \mathrm{HS}^{+}\right.$, and $\mathrm{HS}^{+} \mathrm{FS}^{+}$). The $\mathrm{HS}^{+}$group was included in the analysis to control for the possible influence of $\mathrm{HS}$ in the $\mathrm{HS}^{+} \mathrm{FS}^{+}$group. The two isoforms of DNMT1 have a similar molecular weight of $183 \mathrm{kDa}$ and 


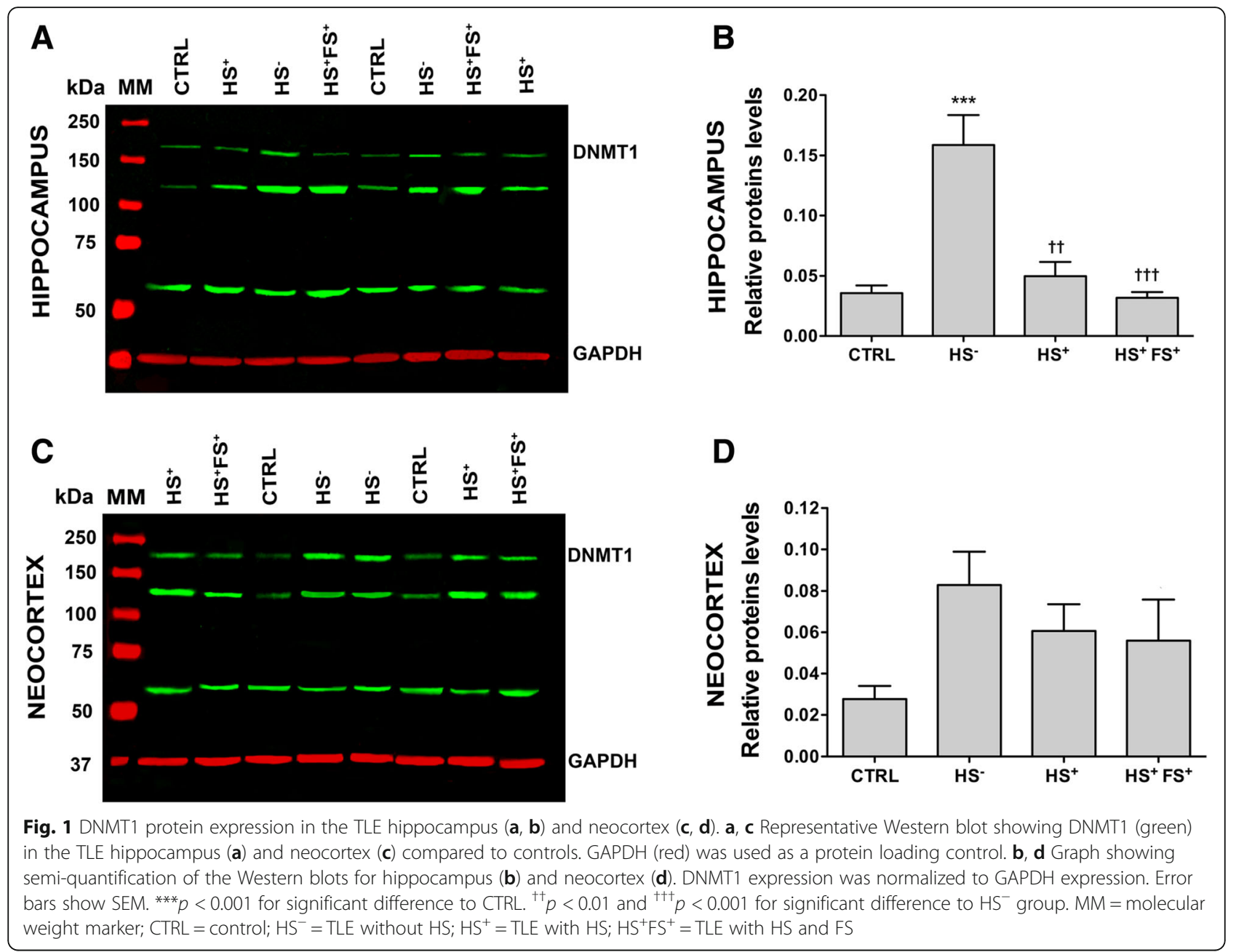

$184 \mathrm{kDa}$, which urged us to quantify both forms together (here referred to as DNMT1). For normalization, we used GAPDH as a control for protein loading. As shown in Additional file $1 \mathrm{~A}$ and $\mathrm{B}$, the expression of GAPDH was not different between control and TLE groups in both types of tissues studied. Western blot analysis for DNMT1 revealed the expected band size for DNMT1, as previously described [36], with two extra bands at lower molecular weights $(\approx 140$ and $60 \mathrm{kDa})$. In the hippocampus, we found a significantly elevated expression of DNMT1 in $\mathrm{HS}^{-}$subjects when compared to the CTRL group and to the other epileptic groups (Fig. 1b). In the neocortex, DNMT1 expression was higher in all epileptics groups compared to the CTRL group but not at a statistically significant level (Fig. 1d). As expression profiles may be influenced by degradation (in relation to increasing post-mortem intervals), we furthermore tested in mice whether the post-mortem interval influenced the expression levels of the DNMT1. For that purpose, we experimentally varied the post-mortem interval in mice and analyzed the expression of the mouse Dnmt1 in the hippocampus and the neocortex by Western blot. As shown in Additional file 2, Dnmt1 expression did not significantly change up to $24 \mathrm{~h}$ post-mortem delay at room temperature neither in the hippocampus (Additional file 2A, B), nor in the temporal neocortex (Additional file 2C, D). Similarly, human DNMT1 expression levels did not correlate with post-mortem interval for human hippocampus and neocortex (Additional file 6, PMI correlation).

Differential expression of DNMT3a isoforms in the human TLE hippocampus and neocortex

As for DNMT1, we analyzed the expression of DNMT3a1 and DNMT3a2 protein isoforms by Western blot in the hippocampus (Fig. 2a) and the temporal neocortex (Fig. 2d) of the same CTRL and TLE groups. GAPDH levels were not significantly different in both tissues studied between CTRL and epilepsy groups (Additional file 1C, D). The blots showed bands of expected size for both isoforms (130 kDa for DNMT3a1 and $81 \mathrm{kDa}$ for DNMT3a2), as previously described [37], 

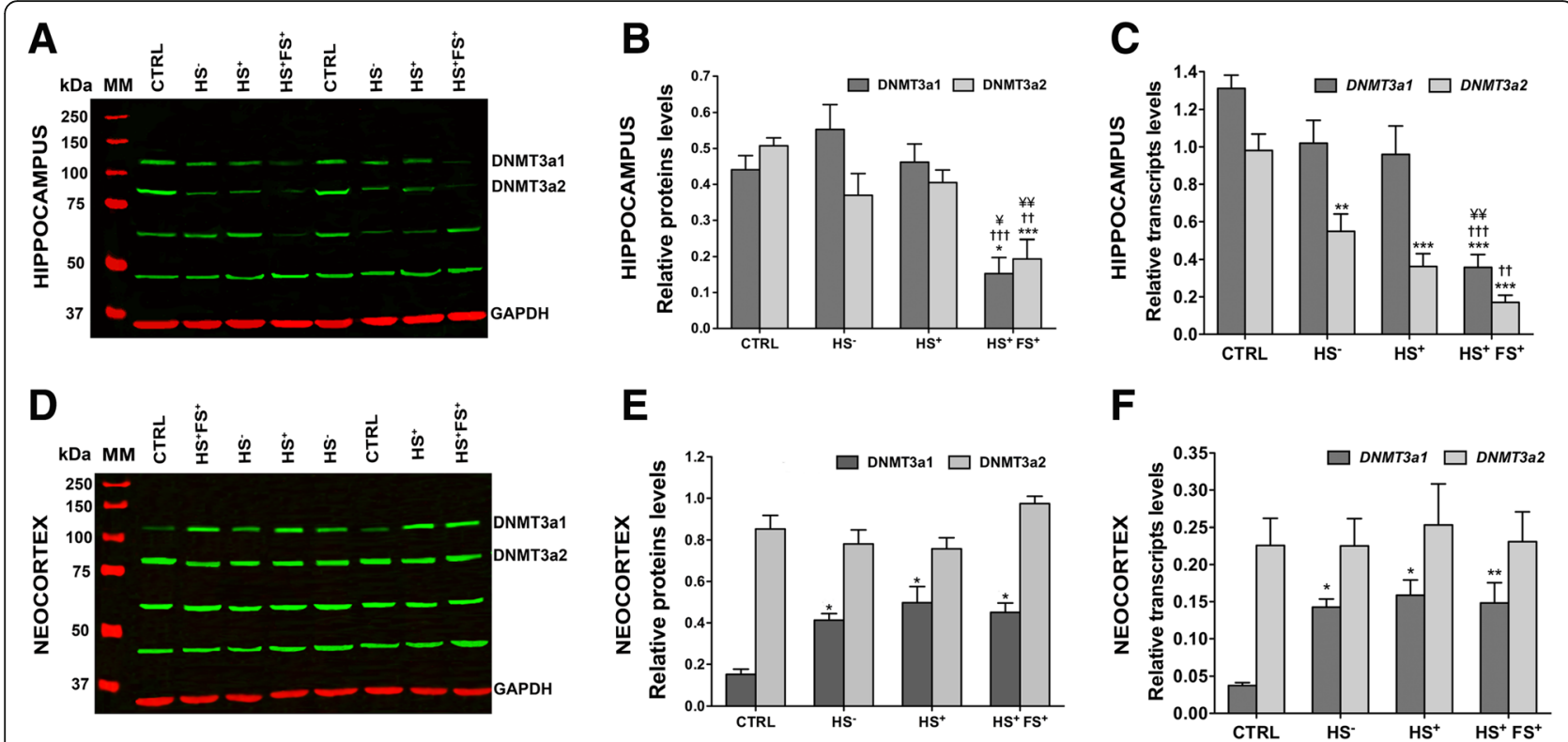

Fig. 2. DNMT3a isoforms expression in the TLE hippocampus (a-c) and neocortex (d-f). $\mathbf{a}, \mathbf{d}$ Representative Western blot showing DNMT3a isoforms (green) in the TLE hippocampus (a) and neocortex (d) compared to control. GAPDH (red) was used as a protein loading control. b, e Graph showing semi-quantification of the Western blots for the hippocampus (b) and neocortex (e). DNMT3a isoforms expression was normalized to GAPDH expression. c, $\mathbf{f}$ Real-time PCR validation of Western blots results for hippocampus (c) and neocortex (f). Error bars show SEM. ${ }^{*} p<0.05,{ }^{* *} p<0.01$, and ${ }^{* * *} p<0.001$ for significant difference to CTRL. ${ }^{\dagger+} p<0.01$ and ${ }^{+\dagger \dagger} p<0.001$ for significant difference to HS ${ }^{-}$group.

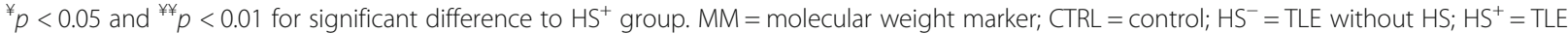
with $\mathrm{HS} \mathrm{HS}^{+} \mathrm{FS}^{+}=$TLE with HS and FS

with two extra bands at lower molecular weights $(\approx 45$ and $60 \mathrm{kDa}$ ). In the hippocampus, we demonstrated that the expression of DNMT3a1 and DNMT3a2 was statistically significantly diminished in $\mathrm{HS}^{+} \mathrm{FS}^{+}$subjects compared to CTRL and other TLE groups (Fig. 2b). In order to confirm these findings at the mRNA level, we performed qRT-PCR (Fig. 2c) and obtained the same results for DNMT3a1. On the other hand, we found that all TLE groups displayed a significant decrease of DNMT3a2 transcript expression compared to CTRL (Fig. 2c). Within the TLE groups, patients with FS showed a significant decrease compared to $\mathrm{HS}^{-}$but not to $\mathrm{HS}^{+}$group (Fig. 2c). By contrast, in the neocortex, the protein (Fig. 2e) and mRNA transcript (Fig. 2f) levels of DNMT3a1 were significantly increased for all TLE groups compared to the CTRL. No changes in the expression of the DNMT3a2 protein and transcript were found in the neocortex (Fig. 2e, f).

In order to exclude the possibility that the reduced DNMT3a levels were the results of degradation, the stability of murine Dnmt3a isoform' protein levels with increasing post-mortem delay was confirmed as described for Dnmt1 (Additional file 3). In addition, human DNMT3 isoform expression did not correlate with postmortem interval neither within the hippocampus nor in the neocortex (Additional file 6, PMI correlation).

\section{Decreased expression of DNMT3a2 isoform in the TLE dentate gyrus of the hippocampus}

In order to further explore whether the decrease in DNMT3a isoforms in TLE hippocampus were specific for different hippocampal sub-regions, we performed immunohistochemistry on the same hippocampal samples using the same antibody used in Western blot experiments. As this antibody recognizes both DNMT3a isoforms, we quantified the expression of both isoforms together (denoted as DNMT3a) and could not specifically analyze DNMT3a1 or DNMT3a2 isoforms using immunohistochemistry. The expression pattern of DNMT3a in the DG is presented in Fig. 3a. The integrated density of DNMT3a immunoreactivity in the DG showed a statistically non-significant decrease in global DNMT3a levels in $\mathrm{HS}^{-}$and $\mathrm{HS}^{+} \mathrm{FS}^{+}$compared to CTRL, whereas the area containing DNMT3a-positive cells showed a statistically significant decrease in $\mathrm{HS}^{+}$and $\mathrm{HS}^{+} \mathrm{FS}^{+}$groups compared to CTRL (Fig. 3c).

To explore to which extent the decrease in DNMT3a2 expression level in the hippocampus (Fig. 2) was mediated via the DG, we performed in situ hybridization with DNMT3a2 mRNA probe (Fig. 4a). Quantifications analysis revealed that all TLE groups displayed a significant decrease of $D N M T 3 a 2$ integrated density and the area expressing DNMT3a2 mRNA compared to CTRL (Fig. 4b, c). Within the TLE groups, patients with FS 


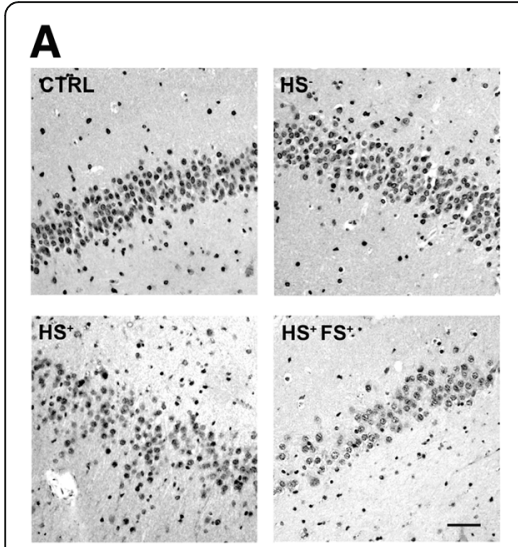

B

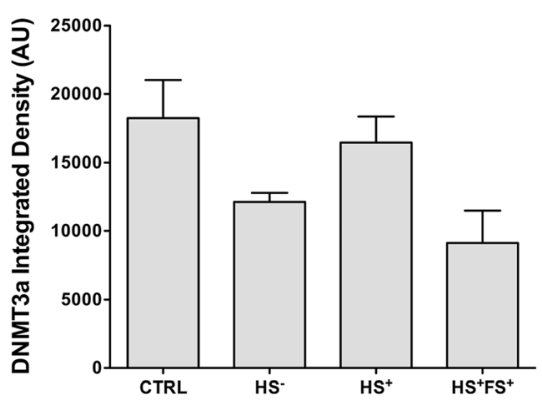

C

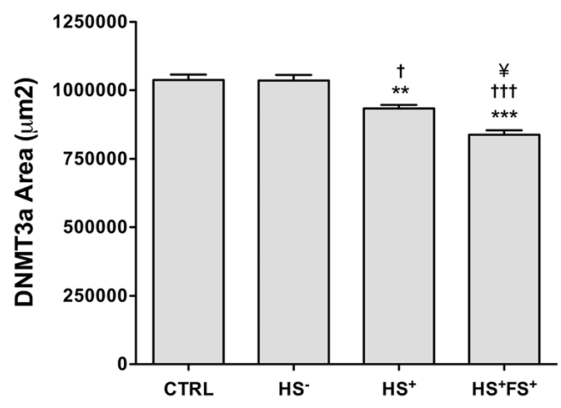

Fig. 3 DNMT3a immunoreactivity in the hippocampal DG. a Representative pictures of DNMT3a staining in the hippocampal DG of TLE patients and controls. Scale bars represent $100 \mu \mathrm{m}$. b ImageJ quantification of the integrated density of DNMT3a staining. c Stereological quantification of the area expressing DNMT3a. Error bars show SEM in $\mathbf{b}$ and CE in $\mathbf{c} .{ }^{* *} p<0.01$ for significant difference to CTRL. ${ }^{\dagger} p<0.05$ and ${ }^{+\dagger} p<0.01$ for significant difference to $\mathrm{HS}^{-}$group. ${ }^{*} p<0.05$ for significant difference to $\mathrm{HS}^{+}$group. $\mathrm{CTRL}=$ control; $\mathrm{HS}^{-}=\mathrm{TLE}$ without $\mathrm{HS}$; $\mathrm{HS}^{+}=\mathrm{TLE}$ with $\mathrm{HS}$; $\mathrm{HS}^{+} \mathrm{FS}^{+}=\mathrm{TLE}$ with $\mathrm{HS}$ and FS.

showed a significant decrease compared to $\mathrm{HS}^{-}$and $\mathrm{HS}^{+}$ groups (Fig. 4c).

For these experiments as well, the post-mortem interval did not correlate with the expression of DNMT3a isoforms (Additional file 6, PMI correlation).

\section{Differences in global 5-mC and 5-hmC levels following TLE}

In order to analyze whether the changes in DNMT1 and DNMT3a expression may have impacted on the global levels of DNA methylation and hydroxymethylation, we analyzed 5-mC and 5-hmC levels by immunohistochemistry in the same hippocampal (Fig. 5) and neocortical tissue samples (Fig. 6). Semi-quantitative image analyses revealed a significant decrease in integrated density of 5-mc and 5-hmc in all TLE groups compared to CTRL (Fig. 5b, e). Moreover, 5-mC integrated density was significantly decreased in $\mathrm{HS}^{+} \mathrm{FS}^{+}$ group compared to $\mathrm{HS}^{-}$and $\mathrm{HS}^{+}$ones (Fig. 5b). The area stained for 5-mc and 5-hmc was significantly decreased in the DG of all TLE groups compared to CTRL (Fig. 5c, f). On the contrary, in the neocortex, 5$\mathrm{mC}$ integrated density was significantly increased in all TLE patients compared to CTRL (Fig. 6b), yet no significant difference in 5-hmC was observed (Fig. 6c, d).

Correlation analyses did not reveal any statistically significant association between the levels of 5- $\mathrm{mC}$ and 5hMC and the post-mortem interval (Additional file 6, PMI correlation).
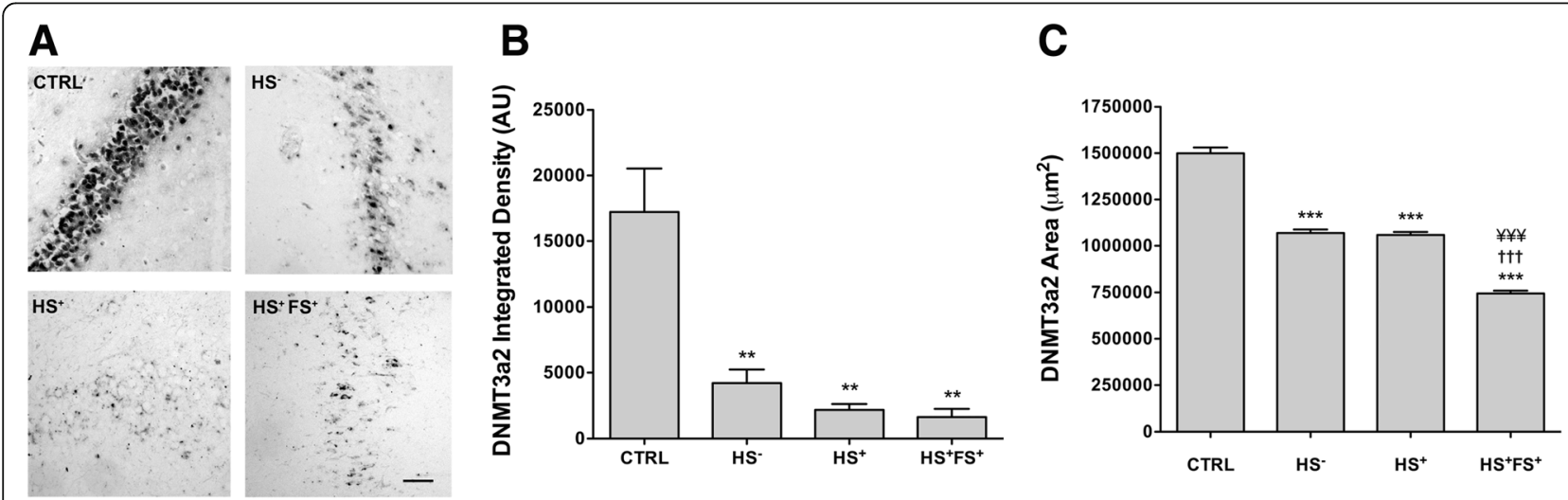

Fig. 4 DNMT3a2 transcript localization in the DG of the hippocampus. a Representative pictures of DNMT3a2 in situ hybridization in the hippocampal DG of TLE patients and controls. Scale bars represent $100 \mu \mathrm{m}$. b ImageJ quantification of the integrated density of DNMT3a2 reactivity. c Stereological quantification of the area expressing DNMT3a2. Error bars show SEM for ImageJ and CE for stereology. ${ }^{* *} p<0.01$ and ${ }^{* * *} p<0.001$ for significant difference to CTRL. ${ }^{++\dagger} p<0.01$ for significant difference to $\mathrm{HS}^{-}$. ${ }^{¥ ¥ ¥} p<0.001$ for significant difference to HS $S^{+}$. CTRL= control; $\mathrm{HS}^{-}=\mathrm{TLE}$ without $\mathrm{HS} ; \mathrm{HS}^{+}=\mathrm{TLE}$ with $\mathrm{HS} ; \mathrm{HS}^{+} \mathrm{FS}^{+}=\mathrm{TLE}$ with $\mathrm{HS}$ and FS. 

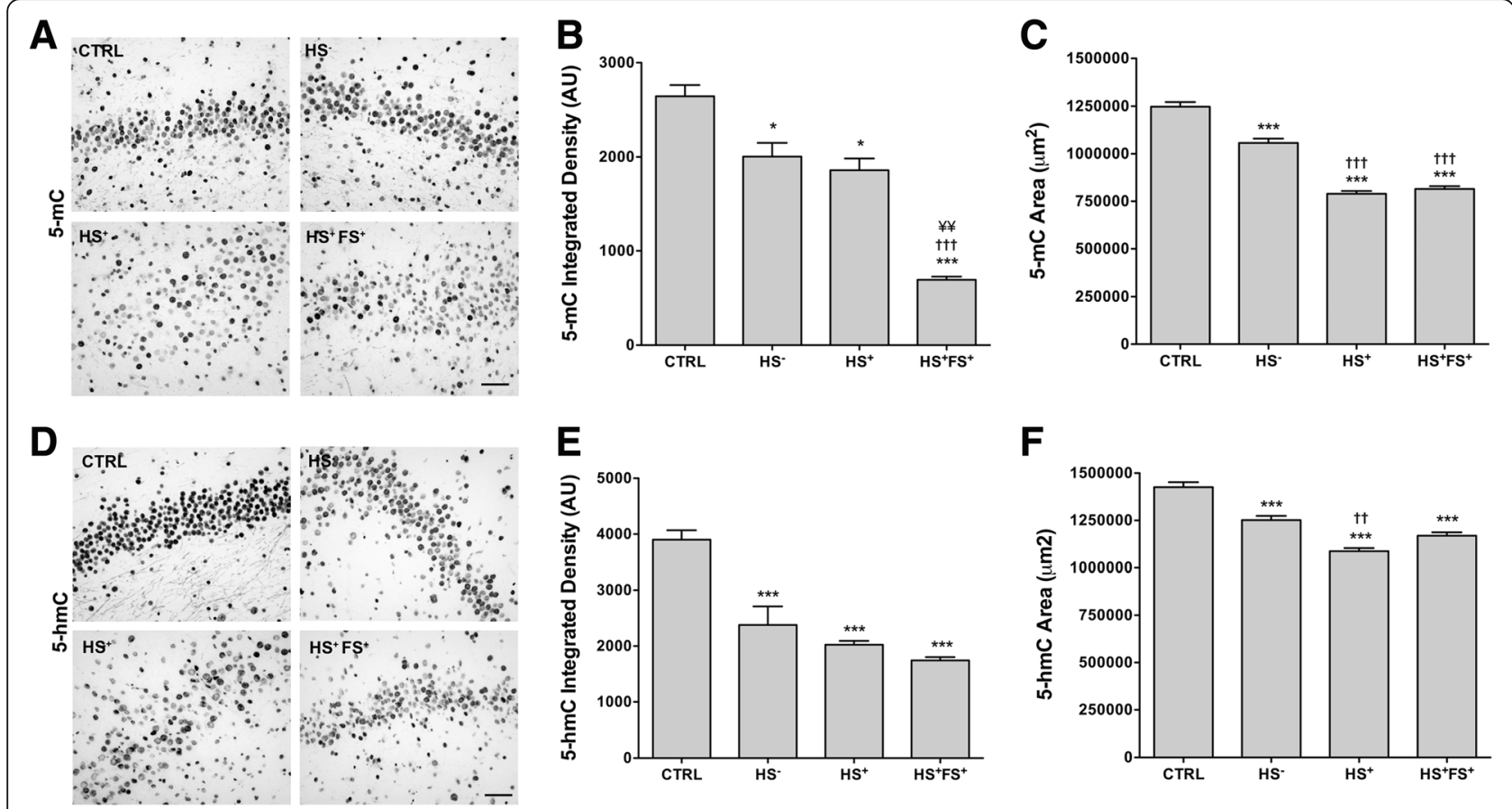

Fig. 5 Global 5-mC and 5-hmc patterns in the hippocampal DG. a, d Representative pictures of 5-mC staining (a) and 5-hmc staining (d) in the hippocampal DG of TLE patients and controls. Scale bars represent $100 \mu \mathrm{m}$. b, e ImageJ quantification of the integrated density of 5-mc staining (b) and 5-hmc staining (e). Error bars show SEM. c, f Stereological quantification of the area expressing 5-mC staining (c) and 5-hmc staining (f). Error bars show CE. $n=3-7$ per group. ${ }^{*} p<0.05$ and ${ }^{* * *} p<0.001$ for significant difference to CTRL. ${ }^{++} p<0.01$ and ${ }^{++t} p<0.001$ for significant

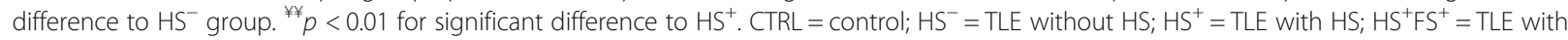
$\mathrm{HS}$ and FS

\section{Discussion}

The main aim of the present cross-sectional pilot study was to make a first step in the exploration of the possible involvement of DNA methylation and DNMT isoforms in the pathophysiology of TLE with or without a history of FS. To our knowledge, this is the first to investigate DNMT isoforms and global DNA (hydroxy)methylation profiles in TLE using specimen from surgically treated TLE patients with HS and a history of FS. In the neocortex, we found an increase of DNMT1 and DNMT3a1 expression and global DNA methylation levels for all TLE groups compared to the CTRL. By contrast, we showed that DNMT3a2, global DNA methylation, and hydroxymethylation levels were profoundly lower in the hippocampus, specifically in the DG, for all TLE groups compared to the CTRL, with a more significant decrease amongst the TLE groups with a history of FS. Remarkably, we demonstrated that DNMT3a1 isoform expression was specifically decreased in the hippocampus of TLE patients with a history of FS compared to epileptic groups without FS and CTRL. A summary of the main findings of this study is presented in Table 1. Together, these results provide the first evidence to support the hypothesis that DNA (hydroxy)methylation, DNMT1, and DNMT3a isoforms may be involved in a brain region-specific manner to mediate differential epileptogenesis in TLE with or without a history of FS.

Our findings in the neocortex are consistent with a previous study from Zhu et al., showing that DNMT1 and DNMT3a protein expression levels were increased in human neocortex from TLE patients without HS [35]. In line with the results of our study of the hippocampus, previous studies on animal models of status epilepticus have demonstrated a decreased Dnmt3a transcript expression and global DNA methylation [31] as well as genome-wide prominent hypomethylation of gene promoters in the hippocampus of cases with epilepsy [29]. In contrast to our results, global DNA methylation patterns were shown to be increased in the hippocampus of a kindling rat model of TLE [33] and in chronic rat epilepsy induced by pilocarpine [30]. Moreover, in the human TLE hippocampus, Kobow et al. found increased methylation of the Reelin promoter associated with granule cell dispersion in the hippocampus [34] and Miller-Delaney and colleagues reported genome-wide hypermethylation in relation to HS [32]. Recently, in a rat model of FS, the expression of Dmnt1 mRNA and protein was found to be increased in the adult hippocampus of animals that experienced FS at post-natal day 

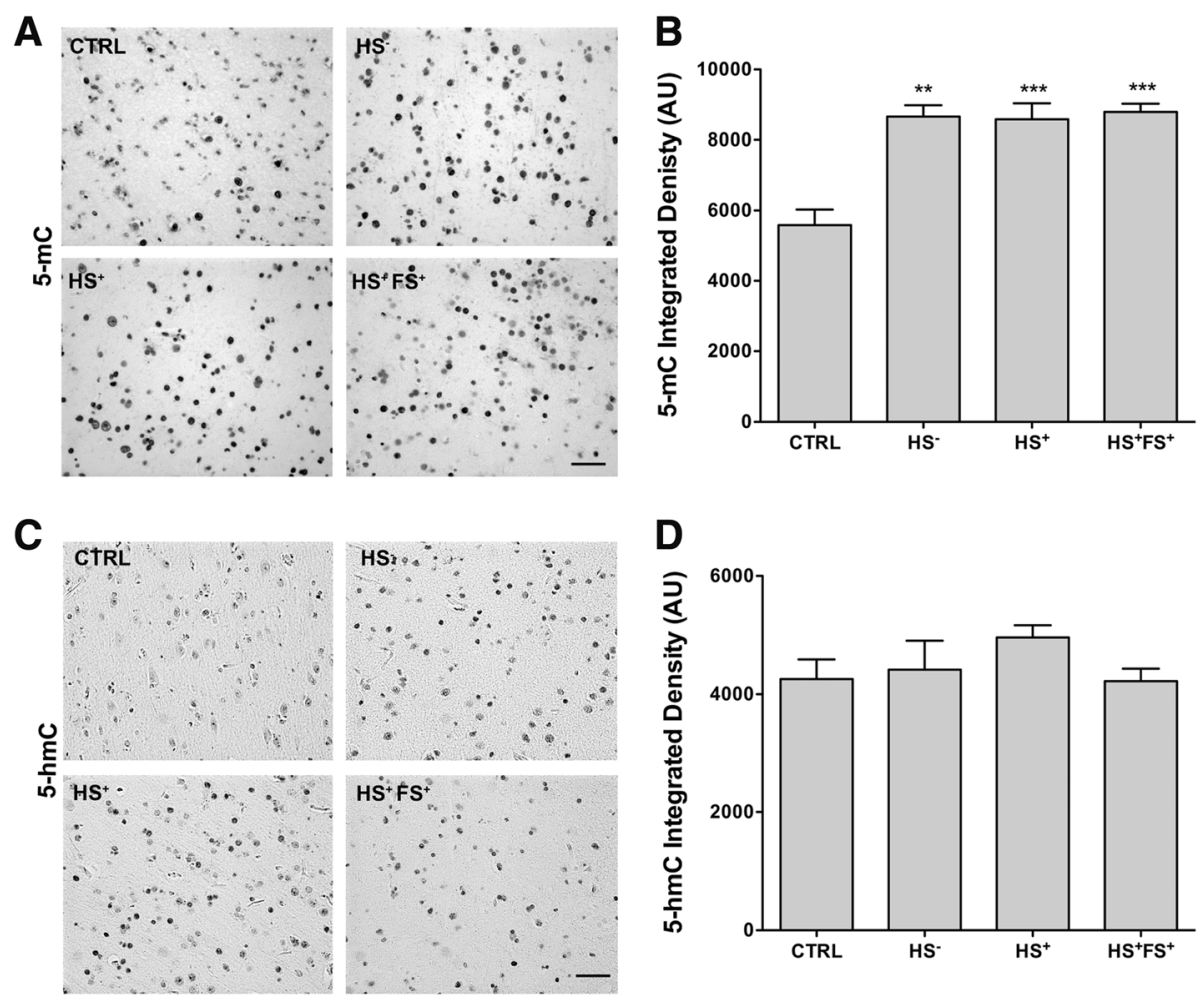

Fig. 6 Global 5-mC and 5-hmc patterns in the neocortex. a, c Representative pictures of 5-mC staining (a) and 5-hmc staining (c) in the neocortex of TLE patients and controls. Scale bars represent $100 \mu \mathrm{m}$. b, d ImageJ quantification of the integrated density of 5-mc staining (b) and 5-hmc staining (d) in the neocortex. $n=6-8$ per group. Error bars show SEM. ${ }^{* *} p<0.01$ and ${ }^{* * *} p<0.001$ for significant difference to CTRL.

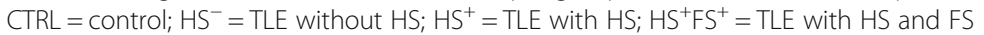

10, while DNMT3a expression did not change [38]. The dissimilarities between our results and other studies might be explained by the different experimental setup and time points (acute vs chronic) used, but further studies are required to prove these possibilities. To summarize, our actual work with prior reports concluded that DNA methylation and DNMTs might play a major role in TLE. However, it also demonstrates that DNA methylation as well as DNMT1 and DNMT3a isoform profiles appear to display brain region-specific patterns potentially depending on the etiology of TLE, the stage of the disease development, and ongoing pathology. This hypothesis is further

Table 1 Summary of the main findings described in this study

\begin{tabular}{|c|c|c|c|c|}
\hline Tissue & Variables measured & Methods & Groups comparison & Effect \\
\hline Neocortex & DNMT1 & WB & All TLE groups vs CTRL & $\uparrow$ \\
\hline Neocortex & $\begin{array}{l}\text { DNMT3a1 } \\
\text { DNMT3a1 }\end{array}$ & WB, qRT-PCR & All TLE groups vs CTRL & $\uparrow$ \\
\hline Neocortex & $5-m C$ & $\mathrm{IHC}$ & All TLE groups vs CTRL & $\uparrow$ \\
\hline Hippocampus & DNMT1 & WB & $\mathrm{HS}^{-}$vs CTRL & $\uparrow$ \\
\hline Hippocampus & DNMT3a2 & qRT-PCR, ISH & All TLE groups vs CTRL & $\downarrow$ \\
\hline Hippocampus & DNMT3a2 & WB & $\begin{array}{l}\mathrm{HS}^{+} \mathrm{FS}^{+} \text {Vs CTRL } \\
\mathrm{HS}^{+} \mathrm{FS}^{+} \text {Vs } \mathrm{HS}^{-} \\
\mathrm{HS}^{+} \mathrm{FS}^{+} \text {VS } \mathrm{HS}^{+}\end{array}$ & $\downarrow$ \\
\hline Hippocampus & $5-\mathrm{mC}, 5 \mathrm{hmC}$ & $\mathrm{IHC}$ & All TLE groups vs CTRL & $\downarrow$ \\
\hline Hippocampus & $\begin{array}{l}\text { DNMT3a1 } \\
\text { DNMT3a1 }\end{array}$ & WB, qRT-PCR & $\begin{array}{l}\mathrm{HS}^{+} \mathrm{FS}^{+} \text {VS CTRL } \\
\mathrm{HS}^{+} \mathrm{FS}^{+} \text {VS } \mathrm{HS}^{-} \\
\mathrm{HS}^{+} \mathrm{FS}^{+} \text {VS } \mathrm{HS}^{+}\end{array}$ & $\downarrow$ \\
\hline
\end{tabular}


supported by recent work showing dissimilarities in genome-wide methylation changes in animal models and human epilepsies with different etiologies [32, 39, 40]. These results are also in accordance with previous studies showing dissociable roles for DNMT1 and DNMT3a in learning and memory, adult behavior, and synaptic plasticity [25, 26, 41, 42].

A major finding in the present study was that the expression of DNMT3a1 and DNMT3a2 and the levels of global DNA methylation were severely decreased in the hippocampus after FS. Molecular and cellular changes have been well-documented to contribute to FS-induced epileptogenesis. For example, an animal model of FS and human TLE has been associated with increased hippocampal neurogenesis [43, 44]. Moreover, FS have been linked to several comorbidities such as memory impairments $[45,46]$. In this regard, one could speculate that FS-induced changes in DNA methylation may transiently or persistently affect gene expression patterns responsible for key phases of the epileptogenesis process and associated comorbidities. In fact, it was demonstrated that DNMT3a play a critical role in adult neurogenesis with DNMT3a deficiency leading to enhanced proliferation of postnatal neuronal stem cells, impaired differentiation to neurons, and increased astrogliogenesis and oligodendrogenesis [47, 48]. In addition, Oliveira and colleagues have reported that DNMT3a2 was an endogenous player in memory formation [27, 28]. Along these lines, cortical infusion of DNMT inhibitors after the establishment of short-term memory has been shown to impair memory consolidation and formation of long-term memory [49]. Therefore, it will be interesting to further investigate (and experimentally test) the possible interpretation of our results, i.e., that decreased expression of DNA methylation, DNMT3a1, and DNMT3a2 could contribute to increased proliferation of newborn cells, astrogliosis, and memory impairment observed in TLE after FS. Clearly, also the cellular mechanisms by which DNMT3a isoforms and DNA methylation contribute to gene expression and cellular changes in FS-induced epileptogenesis need further investigation in rodent models of FS and in human TLE.

There are some limitations of the present study. The first one is that our investigation is a pilot study that was performed using a small sample size. However, the post hoc power calculation demonstrated that the statistically significant results obtained were supported by a power higher than $80 \%$. Another constraint is the lack of age- and gender-matched groups. To circumvent that issue, we included age and gender as confounding factors in the statistical analysis. Moreover, because of the cross-sectional design of the study, we were not able to disentangle whether the observed epigenetic changes are the cause or the consequence of TLE development.
Therefore, our main findings should be replicated using a larger cohort matched for age and gender and with a longitudinal design to test for causality.

Another caveat is that post-mortem controls may contain autopsy delay that alters the expression of DNMTs and DNA methylation profiles. The simulation of the post-mortem delay in our murine experiment showed that Dnmt1 and Dnmt3a isoform' proteins levels were stable until 24h after death. Regarding DNA (hydroxy)methylation, it has been shown that 5-mC and 5-hmC are stable for more than $48 \mathrm{~h}$ post-mortem in human, pig, and mouse brain [50]. Of note, the longer post-mortem interval of our study is $42 \mathrm{~h}$. In addition, correlations analysis between DNMT isoform expressions, 5$\mathrm{mC}$ and 5-hmC levels, and post-mortem interval did not show statistically significant relationship. Together, these indications suggest that the post-mortem delay most likely did not influence the results of our study; however, we could not completely exclude a potential effect.

The use of whole tissue for Western blot and qPCR analyses did not allow to distinguish differences in DNMT isoform expression between hippocampal subfield and cell types (e.g., glia and neurons). Future studies using cell sorting or laser capture microdissected tissues may be able to feature cell type- and subregionspecific epigenetic changes that occur in TLE with or without FS history.

Another important limitation is the measurements of global 5-mC and 5-hmC levels that are unable to specify where in the genome methylation alterations have occurred. A large number of genes might be involved in the development of TLE, each of them is likely to exhibit unique changes in methylation patterns, and depending on the direction of those changes, effects could be washed out in a global assessment. Therefore, future studies investigating gene-specific methylation profiles and gene expression are needed.

Finally, the influence of antiepileptic drugs on DNA methylation status should be taken into consideration. Notably, the effects of antiepileptic drugs on epigenetic factors are not fully understood (for review, see [51]). In this study, long-term treatment of all patients with a combination of several antiepileptic drugs was used before surgery resections and we could not exclude any direct or indirect effect of these drugs on DNMT expression and global (hydroxy)methylation patterns. Future studies using animal models of TLE should be conducted to unravel the potential influence of antiepileptic drugs on DNA methylation.

\section{Conclusion}

In summary, the findings of our descriptive cross-sectional pilot study demonstrated a brain region-specific different pattern of DNMT1 and DNMT3a isoform expression, as 
well as DNA methylation and hydroxymethylation levels in TLE patients with or without a history of FS. Our results specifically suggest a potential involvement of DNMT3a isoforms in FS-induced epileptogenesis. Therefore, DNMT3a isoforms represent interesting targets for further experimental studies to explore the pathophysiology of TLE with different etiologies and to investigate the causality between FS and TLE. Clearly, the assumed correlation between neuronal hyperexcitability after FS, DNA methylation, and DNMTs needs further study as understanding the exact pathophysiological mechanisms may contribute to the identification of disease biomarkers and new treatment strategies to drug-resistant epilepsy or for preventing FS-induced epileptogenesis.

\section{Materials and methods}

\section{Human brain tissue}

Human hippocampi and neocortices were collected at Maastricht University Medical Center (MUMC) as previously described [52]. In total, 22 TLE patients were included, of which 14 did not show any signs of $\mathrm{HS}\left(\mathrm{HS}^{-}\right)$, 10 had the diagnostic of $\mathrm{HS}\left(\mathrm{HS}^{+}\right)$, and 13 had $\mathrm{HS}$ with a history of FS in childhood $\left(\mathrm{HS}^{+} \mathrm{FS}^{+}\right)$. Patient demographics are presented in Table 2.

Human control tissue samples (CTRL, $n=10$ ) were obtained from autopsy. These control patients died of causes not related to a known neurological disease. Average autopsy delay was $16.7 \pm 3.8 \mathrm{~h}$ (Table 2 ).

A detailed description of the samples that were used for the different analyses is presented in the Additional file 4.

The sample size of our study is within the range of other studies that analyzed epigenetic mechanism in human TLE samples [32, 34, 35].

\section{Western blot}

Frozen human hippocampus (containing all hippocampal subregions) and neocortex tissues were homogenized in lysis buffer (50 mM Tris- $\mathrm{HCl}$ ( $\mathrm{pH} 7.5), 0.01 \mathrm{M}$ phosphatebuffered saline (PBS), 1\% Igepal, 0.1\% Triton X-100, $1 \mathrm{mM}$ EDTA, $1 \mathrm{mM}$ EGTA, and protease inhibitors cocktail (Complete, Roche) using a Mini-Beadbeater (GlenMills). Lysates were incubated on ice for $30 \mathrm{~min}$ and subsequently clarified by centrifugation at $16,000 \times g$ for $20 \mathrm{~min}$ at $4{ }^{\circ} \mathrm{C}$. Protein concentrations were determined using the DC protein assay (BioRad). Total proteins (50 $\mu$ g per lane) were separated using a 6 or $8 \%$ SDS-PAGE for DNMT1 and DNMT3a, respectively. Each sample was run in triplicate. Proteins were subsequently transferred to a nitrocellulose membrane (Merck Millipore) for $16 \mathrm{~h}$ at $90 \mathrm{~mA}$. After 5 min washing in PBS and $1 \mathrm{~h}$ blocking in Odyssey Blocking buffer (LI-COR) diluted 1:2 in PBS, the membranes were incubated for $1 \mathrm{~h}$ at room temperature with primary antibodies diluted in Odyssey blocking buffer-
PBS 1:2 (rabbit anti-DNMT1, sc-20701, Santa Cruz, 1:200; rabbit anti-DNMT3a, sc-20703, Santa Cruz, 1:500; mouse anti-GAPDH, 10R-G109A, Fitzgerald, 1:2,000,000). Membranes were washed once in PBS-0.1\% Tween 20 (PBS-T) and twice in PBS for 10 min each and subsequently incubated for $1 \mathrm{~h}$ at room temperature with the secondary antibodies diluted in Odyssey Blocking buffer-PBS 1:2 (donkey anti-mouse IRDye 670 and goat anti-rabbit IRDye 800 , LI-COR, 1:10,000). After three washings of $10 \mathrm{~min}$ (PBS-T, PBS, PBS), immunoreactive protein bands were visualized by an Odyssey Infrared Imaging System (Li-COR).

Immunoblots were analyzed with Image J software. Relative pixel intensities were measured, and the background signal was subtracted. DNMT1 and DNMT3a isoform intensities were corrected by their respective GAPDH expression (relative protein levels).

The validations of DNMT1 and DNMT3a antibodies are described by $\mathrm{He}$ et al. [36] and Challen et al. [37], respectively.

\section{qRT-PCR}

Total RNA was isolated from frozen human hippocampi and neocortices using the TRIzol reagent (Invitrogen) following the manufacturer's instructions. RNA was quantified on a NanoDrop 1000 spectrophotometer (NanoDrop Technologies). One microgram of total RNA was converted into first-strand cDNA with oligo(dT) primers using RevertAid First Strand cDNA Synthesis Kit (Thermo Scientific) as described by the manufacturer. qPCR experiments were performed using the Roche 480 LightCycler (Roche Applied Science) with SensiMix SYBR Hi-ROX (Bioline) and specific primers listed in Additional file 5. Minus reverse transcription and non-template controls were used to control for genomic DNA and cross-well contamination, respectively. All samples were run in triplicates, and triplicates discordant in $\mathrm{Cq}$ by more than 0.5 cycles were excluded from the analysis. For normalization of mRNA expression, RefFinder was used to find the most stable reference gene among YWHAZ, RPL13a, TBP, and NSE. For hippocampus, the relative abundance of mRNAs was standardized with the geometric mean of TBP/NSE mRNA, as previously reported [53], while for the neocortex, RPL13a and TBP were used. Mean normalized expression was calculated by the Pfaffl method that accounts for amplification efficiencies.

\section{Immunohistochemistry}

Formalin-fixed paraffin-embedded tissues were cut at $5 \mu \mathrm{m}$ on the microtome (Leica). Sections were transferred onto SuperFrost Plus slides (VWR) and dried overnight at $37^{\circ} \mathrm{C}$. Slices were deparaffinized and subsequently subjected to antigen retrieval in $0.01 \mathrm{M}$ citrate buffer pH 6 for $20 \mathrm{~min}$ at $95{ }^{\circ} \mathrm{C}$. After cooling down at 
Table 2 Clinical characteristics of TLE patients and post-mortem controls

\begin{tabular}{|c|c|c|c|c|c|c|}
\hline Controls & Gender & Age (years) & PMI (h) & \multicolumn{2}{|c|}{ Cause of death } & Resection side \\
\hline C1302 & Male & 62 & 20 & \multicolumn{2}{|l|}{ Sepsis } & Right \\
\hline C1303 & Male & 66 & 39 & \multicolumn{2}{|c|}{ Heart failure } & Right \\
\hline C1304 & Male & 76 & 14 & \multicolumn{2}{|l|}{ Sepsis } & Left \\
\hline C1401 & Male & 80 & 22 & \multicolumn{2}{|c|}{ Heart failure } & Right \\
\hline C1402 & Male & 66 & 14 & \multicolumn{2}{|l|}{ Sepsis } & Right \\
\hline C1403 & Male & 61 & 19 & \multicolumn{2}{|c|}{ Heart failure } & Right \\
\hline C1404 & Female & 84 & 13 & \multicolumn{2}{|c|}{ Abdominal carcinoma } & Right \\
\hline C1405 & Female & 64 & 42 & \multicolumn{2}{|l|}{ COPD } & Right \\
\hline C1406 & Female & 85 & 17 & \multicolumn{2}{|c|}{ Lung carcinoma } & Right \\
\hline C1407 & Male & 83 & 12 & \multicolumn{2}{|c|}{ Heart failure } & Right \\
\hline TLE patients & Gender & Age at surgery (years) & Age of onset (years) & Duration & Pathology & Antiepileptic drugs \\
\hline E1011 & Male & 58 & 53 & 5 & $\mathrm{HS}^{-}$ & VPA, CBZ, LTG, LEV \\
\hline E1013 & Female & 51 & 24 & 27 & $\mathrm{HS}^{-}$ & LEV, CBZ, LTG \\
\hline E1016 & Male & 37 & 31 & 6 & $\mathrm{HS}^{-}$ & LEV, VPA, CBZ, LTG \\
\hline E1107 & Female & 60 & 17 & 43 & $\mathrm{HS}^{-}$ & LTG, CBZ, LEV, CLB \\
\hline E1204 & Female & 40 & 16 & 24 & $\mathrm{HS}^{-}$ & PHT, DZP, OXC, CLZ \\
\hline E1205 & Male & 20 & N/A & N/A & $\mathrm{HS}^{-}$ & N/A \\
\hline E1206 & Male & 47 & 31 & 16 & $\mathrm{HS}^{-}$ & CLB, OXC, LEV \\
\hline E1207 & Male & 29 & 20 & 9 & $\mathrm{HS}^{-}$ & OXC, LEV \\
\hline E1214 & Female & 39 & 30 & 9 & $\mathrm{HS}^{-}$ & LTG, CBZ \\
\hline E1302 & Female & 21 & 20 & 1 & $\mathrm{HS}^{-}$ & LEV, LAC \\
\hline E1306 & Female & 59 & 7 & 52 & $\mathrm{HS}^{-}$ & $\mathrm{CBZ}, \mathrm{CLB}$ \\
\hline E1319 & Female & 41 & 27 & 14 & $\mathrm{HS}^{-}$ & LEV, CBZ, CLB \\
\hline E1402 & Female & 21 & 1 & 20 & $\mathrm{HS}^{-}$ & CLE, LEV \\
\hline E1404 & Male & 19 & 8 & 8 & $\mathrm{HS}^{-}$ & CBZ, CLZ, LEV \\
\hline E1009 & Female & 39 & 4 & 35 & $\mathrm{HS}^{+}$ & DZP, CLB, LEV, OXC \\
\hline E1018 & Male & 63 & 2.5 & 60.5 & $\mathrm{HS}^{+}$ & $\mathrm{CBZ}, \mathrm{CLB}, \mathrm{PHT}, \mathrm{CLZ}$ \\
\hline E1019 & Female & 43 & 3 & 40 & $\mathrm{HS}^{+}$ & LTG, CLZ, DZP, LEV, CLB \\
\hline E1103 & Female & 58 & 54 & 4 & $\mathrm{HS}^{+}$ & LTG, LEV, OXC, CBZ \\
\hline E1104 & Male & 47 & 3 & 44 & $\mathrm{HS}^{+}$ & LEV, PHT \\
\hline E1217 & Male & 54 & 17 & 37 & $\mathrm{HS}^{+}$ & FLU, LTG, MET, ZOP \\
\hline E1218 & Male & 28 & 4 & 24 & $\mathrm{HS}^{+}$ & CBZ, LTG \\
\hline E1312 & Female & 23 & 19 & 4 & $\mathrm{HS}^{+}$ & MDZ \\
\hline E1318 & Female & 47 & 11 & 36 & $\mathrm{HS}^{+}$ & LTG, CLB, TMP, VPA \\
\hline E1407 & Male & 55 & 10 & 45 & $\mathrm{HS}^{+}$ & MDZ, CBZ, CLB, LEV \\
\hline E0109 & Male & 48 & 30 & 18 & $\mathrm{HS}^{+} \mathrm{FS}^{+}$ & LTG, CLB, TPM \\
\hline E0705 & Female & 23 & 6 & 16 & $\mathrm{HS}^{+} \mathrm{FS}^{+}$ & LEV, LTG, CLB \\
\hline E0707 & Female & 59 & N/A & N/A & $\mathrm{HS}^{+} \mathrm{FS}^{+}$ & OXC, CLB, LEV \\
\hline E1014 & Female & 50 & 47 & 3 & $\mathrm{HS}^{+} \mathrm{FS}^{+}$ & OXC, LEV, CLB \\
\hline E1017 & Female & 23 & 1 & 22 & $\mathrm{HS}^{+} \mathrm{FS}^{+}$ & LTG, TPM, CLB, OXC \\
\hline E1213 & Male & 60 & 2 & 58 & $\mathrm{HS}^{+} \mathrm{FS}^{+}$ & CBZ, VPA, LTG, DZP \\
\hline E1219 & Male & 36 & 9 & 27 & $\mathrm{HS}^{+} \mathrm{FS}^{+}$ & LEV, VPA, OXC \\
\hline
\end{tabular}


Table 2 Clinical characteristics of TLE patients and post-mortem controls (Continued)

\begin{tabular}{lllllll}
\hline E1221 & Female & 41 & 4 & 37 & $\mathrm{HS}^{+} F S^{+}$ & $\mathrm{CLZ}, \mathrm{CBZ}$ \\
E1305 & Female & 20 & 1 & 19 & $\mathrm{HS}^{+} \mathrm{FS}^{+}$ & MDZ, LEV, TMP \\
E1310 & Female & 43 & 28 & 15 & $\mathrm{HS}^{+} \mathrm{FS}^{+}$ & $\mathrm{LEV}, \mathrm{LTG}, \mathrm{CLB}$ \\
E1314 & Male & 42 & 8 & 34 & $\mathrm{HS}^{+} \mathrm{FS}^{+}$ & $\mathrm{LTG}, \mathrm{CLB}$ \\
E1408 & Male & 33 & 0 & 33 & $\mathrm{HS}^{+} \mathrm{FS}^{+}$ & $\mathrm{CBZ}, \mathrm{CLB}, \mathrm{MDZ}$ \\
E1416 & Female & 41 & 20 & 21 & $\mathrm{HS}^{+} \mathrm{SS}^{+}$ & LEV, LTG, CLB \\
\hline
\end{tabular}

CBZ carbamazepine, CLB clobazam, CLZ clonazepam, DZP diazepam, FLU flupentixol, FS febrile seizures, HS hippocampal sclerosis, LAC lascosamide, LEV levotiracetam, $L T G$ lamotrigine, MDZ midazolam, MET methotrimeprazine, OXC oxcarbazepine, $P H T$ phenytoin, $P M I$ post-mortem interval, $T L E$ temporal lobe epilepsy, TPM topiramate, VPA valproic acid, ZOP zopiclone, N/A not available

room temperature for $20 \mathrm{~min}$, sections were washed three times in $1 \mathrm{M}$ tris-buffered saline (TBS) 5 min each. After incubation in TBS containing $1 \% \mathrm{H}_{2} \mathrm{O}_{2}$ for $30 \mathrm{~min}$ at room temperature, slides were washed three times 5 min in respectively TBS-triton $0.3 \%$ (TBS-T), TBS, and TBS-T. Sections were blocked for $30 \mathrm{~min}$ at room temperature in TBS-T with 3\% normal donkey serum (NDS) before incubation with primary antibodies diluted in TBS-T $0.3 \%$ NDS for overnight at $4{ }^{\circ} \mathrm{C}$ (rabbit anti-5hmC, Active Motive, 1:5000; mousse anti-5-mC, Genway Biotech, 1:1000; rabbit anti-DNMT3a, sc-20703, Santa Cruz, 1:500). Slides were washed three times $5 \mathrm{~min}$ in TBS-T, TBS, and TBS-T at room temperature. Then, sections were incubated for $1 \mathrm{~h}$ at room temperature with secondary antibodies diluted in TBS-T 0.3\% NDS (biotinylated donkey anti-rabbit or anti-mouse, Jackson ImmunoResearch, 1:200). After three washing in TBS-T, TBS, and TBS-T (5 min each), slides were incubated for $2 \mathrm{~h}$ at room temperature with Vectastain ABC kit (Vector Laboratories) diluted 1:500 in TBS-T. Slides were then washed two times in TBS and one time in Tris- $\mathrm{HCl}$ $0.05 \mathrm{M}$ ( $\mathrm{pH} 7.6$ ), and subsequently incubated in 3,3' -Diaminobenzidine (DAB)-Peroxidase Substrate solution (0.05\% DAB, $0.015 \% \mathrm{H}_{2} \mathrm{O}_{2}$, Tris- $\mathrm{HCl} 0.025 \mathrm{M}, \mathrm{pH} 7.6$ ) for $10 \mathrm{~min}$ and washed three times $5 \mathrm{~min}$ each in TBS at room temperature. Slides were dehydrated and coverslipped using Pertex mounting medium (HistoLab). Pictures were taken with an Olympus AX70 microscope with bright field illumination coupled to a digital camera (f-view, Olympus) as previously described [52].

\section{In situ hybridization}

Formalin-fixed paraffin-embedded tissues were cut at $5 \mu \mathrm{m}$ on the microtome (Leica). Sections were transferred onto SuperFrost Plus slides (VWR) and dried overnight at $37{ }^{\circ} \mathrm{C}$. Slices were deparaffinized in xylene, decreasing concentrations in ethanol solutions and PBS at room temperature then treated with $15 \mu \mathrm{g} / \mathrm{ml}$ of Proteinase $\mathrm{K}$ for $10 \mathrm{~min}$ at $37{ }^{\circ} \mathrm{C}$. Slides were incubated with pre-hybridization solution (USBiological) for $3 \mathrm{~h}$ at $60{ }^{\circ} \mathrm{C}$ and then hybridized with $40 \mathrm{nM}$ double-DIG-LNA probe (Exiqon) complementary to DNMT3a2 mRNA overnight at $55{ }^{\circ} \mathrm{C}$. Slides were washed in the following buffers for
10 min each at $55^{\circ} \mathrm{C}$ : twice in $5 \times$ standard saline sodium citrate (SSC), once in $2 \times \mathrm{SSC}$, three times in $5 \mathrm{M}$ tetramethylammonium chloride (TMAC), and twice in $2 \times$ SSC. Treatment with $1 \mu \mathrm{g} / \mathrm{ml}$ Proteinase $\mathrm{K}$ in $2 \times \mathrm{SSC}$ was done for $30 \mathrm{~min}$ at $55^{\circ} \mathrm{C}$ before another series of washing steps of $5 \mathrm{~min}$ each: $2 \times \mathrm{SSC}, 1 \times \mathrm{SSC}$, and $0.2 \times$ SSC (all at $55^{\circ} \mathrm{C}$ ), two times in $0.2 \times \mathrm{SSC}$ at $37^{\circ} \mathrm{C}$ and once in $0.2 \times \mathrm{SSC}$ at room temperature. Slides were then rinsed twice with PBS for $10 \mathrm{~min}$ at room temperature, blocked for $1 \mathrm{~h}$ in blocking solution (USBiological), and incubated with anti-DIG alkaline phosphatase-conjugated antibody overnight at $4{ }^{\circ} \mathrm{C}$ (USBiological). Tissues were washed with Alkaline Phosphatase buffer twice for $5 \mathrm{~min}$ at room temperature and subsequently incubated in nitroblue tetrazolium/5-bromo-4-chloro-3indolyl phosphate (NBT/BCIP) color substrate at room temperature in the dark for $72 \mathrm{~h}$. The slides were rinsed with water, coverslipped with aqua mount (Lerner Laboratory). Positive controls and no-probe controls were included for each hybridization procedure.

\section{Microscopy and image analysis}

For intensity measurements, images were taken with the $\times 10$ objective using a bright-field filter for each staining. All images were taken using identical camera, microscope lens, and light settings. One hippocampal/neocortex section was used per each staining, where images were taken from five sites in the DG per subject. All images for signal intensity analysis were taken with Olympus AX70 Grey value microscope. ImageJ version $1.51 \mathrm{j} 8$ was used to calculate the integrated density of the staining. The threshold baseline was calculated by averaging the thresholds of three randomly selected DG pictures (beginning, middle, and end) from all the sections, both control and TLE slides. The setting was as follows: image was inverted, type was 32 bits, background pixel was set to $\mathrm{NaN}$, and set measurements were area, mean gray value, standard deviation, min and max gray value, and integrated density.

For stereology measurements, live image of DNMT3a, 5-mC, and 5-hmC stained slides were observed under bright field using the stereology microscope Olympus BX51. The configuration of the stereology microscope 
consists of Olympus BX51, LEP MAC5000, and MBF CX9000 camera. The DG expressing the desired probe was manually drawn using StereoInvestigator program at $\times 10$ magnification. The software automatically quantified the area $\left(\mu \mathrm{m}^{2}\right)$ with its corresponding coefficient of error $(\mathrm{CE})$.

\section{Murin post-mortem interval}

NMRI mice were killed by cervical dislocation. Hippocampus and temporal neocortex tissues were collected either immediately after death or following a $1,8,16$, or $24 \mathrm{~h}$ delay at room temperature. Tissue samples were dissected in PBS at $4{ }^{\circ} \mathrm{C}$, immediately frozen on dry ice and stored at $-80^{\circ} \mathrm{C}$. Mice were provided by the GIGA-neuroscience department of the University of Liège. They were used for another study involving embryonic research. They were treated according to the guidelines of Belgian Ministry of Agriculture in agreement with European Community Laboratory Animal Care and Use Regulations.

\section{Statistics}

Statistical analyses were carried out using RStudio (version 1.2.1335), and graphs were built using GraphPad Prism software (version 5.0a). Values are either presented as mean and standard error of the mean or presented as mean and coefficient of error (Stereology). The normal distribution of the data was proved using the Shapiro-Wilk test. The oneway ANOVA followed by Bonferroni post hoc was used to test for multiple comparisons between groups. Age and gender have been used as confounding factors in the analyses. Correlation analyses were done by calculating the Pearson's correlation coefficient. Differences between the groups were considered significant for $p \leq 0.05$. During experiments, the experimenter was blinded to the experimental condition to prevent biased assessment. Cohen's $d$ effect size was used to perform two-tail post hoc power analysis using G*Power software (version 3.1.9.4) [54]. A summary of the statistical analysis is provided in Additional file 6.

\section{Additional files}

Additional file 1: GAPDH expression levels in Western blots analysis. Quantification of the expression levels of GAPDH in the Western blots analyzing DNMT1 (A, B) and DNMT3a (C, D) in the hippocampus and the neocortex. (PDF $1126 \mathrm{~kb}$ )

Additional file 2: Effect of post-mortem interval on murine Dnmt1 expression. (A, C) Representative Western blots of Dnmt1 (green) in the mouse hippocampus (A) and neocortex (C) extracted immediately ( $0 \mathrm{~h}$ ) or after $1,8,16$, or $24 \mathrm{~h}$ delay at room temperature. Gapdh (red) was used as a protein loading control. ( $B, D)$ Graph showing semiquantification of the Western blots ( $n=2$ per time point) for the hippocampus (B) and neocortex (D). Data are presented as relative expression normalized to Gapdh. Error bars show SEM. MM: molecular weight marker. (PDF 3164 kb)

Additional file 3: Effect of post-mortem interval on murine Dnmt3a isoforms expression. (A, C) Representative Western blots of the various
Dnmt3a isoforms (green) in the mouse hippocampus (A) and neocortex (C) extracted immediately $(0 \mathrm{~h})$ or after $1,8,16$ or $24 \mathrm{~h}$ delay at room temperature. Gapdh (red) was used as a protein loading control. (B, D) Graph showing semi-quantification of the Western blots ( $n=2$ per time point) for the hippocampus (B) and neocortex (D). Data are presented as relative expression normalized to Gapdh. Error bars show SEM. MM: molecular weight marker. (PDF $2061 \mathrm{~kb}$ )

Additional file 4: Detailed description of the clinical characteristics of TLE patients and post-mortem controls. (XLSX $43 \mathrm{~kb}$ )

Additional file 5: Sequences of the qPCR primers. (XLSX $35 \mathrm{~kb}$ )

Additional file 6: Summary of the statistics. (XLSX 37 kb)

\section{Abbreviations}

5-hmC: 5-Hydroxymethylcytosine; 5-mC: 5-Methylcytosine; CA: Cornu ammonis; CTRL: Control; DG: Dentate gyrus; DNMT: Methyltransferase; FS: Febrile seizures; HS: Hippocampal sclerosis; TLE: Temporal lobe epilepsy

\section{Acknowledgements}

The authors would like to thank Laurie Medard from the GIGA-Neurosciences department of the University of Liège for the dissection of the NMRI mice tissues.

\section{Authors' contributions}

$\mathrm{GH}, \mathrm{BPFR}, \mathrm{DLAvdH}$, and LdN designed the study. LdN, KC, and HS performed the experiments and the analysis. OS and JD collected human TLE tissue samples, and $\mathrm{GH}$ gathered post-mortem tissues. LdN and KC wrote the manuscript. All authors critically read, approved, and commented on the final manuscript.

\section{Funding}

Funds have been provided by the Internationale Stichting Alzheimer Onderzoek (ISAO) grant 13515 (BPFR). LdN was supported by the F.R.S-FNRS as a post-doctoral researcher.

\section{Availability of data and materials}

The datasets used and analyzed during the current study are available from the corresponding author on reasonable request. Personal sensitive data from patients will not be made available for ethical reasons.

Ethics approval and consent to participate

A written informed consent was signed by the patients for the use of their resected tissue samples for medical research. According to the Dutch legislation, the approval of local ethics committee for medical research with patient data and tissue samples is not mandatory. At the time of tissue collection for this study, ethical approval was deemed unnecessary not only because of this legislation but also because the tissue collection did not determine the course of the surgery nor of the preceding and follow-up treatment, and the investigated samples would otherwise have been discarded. All tissue samples and patient data were anonymized for the members of the experimental research team, and these members did not have any contact with the operated patients.

Competing interests

The authors declare that they have no competing interests.

\section{Author details}

${ }^{1}$ School for Mental Health and Neuroscience (MHeNS), Department of Psychiatry and Neuropsychology, Faculty of Health, Medicine and Life Sciences, Maastricht University, Universiteitssingel 50, 6229, ER, Maastricht, The Netherlands. ${ }^{2}$ GIGA-Neurosciences, University of Liège, Liège, Belgium. ${ }^{3}$ Department of Psychiatry, Psychosomatics and Psychotherapy, University of Würzburg, Würzburg, Germany. ${ }^{4}$ Department of Neurosurgery, Maastricht University Medical Center, Maastricht, The Netherlands. ${ }^{5}$ Academic Center for Epileptology (ACE), Maastricht University Medical Center, Maastricht, The Netherlands. 
Received: 17 January 2019 Accepted: 2 August 2019

\section{Published online: 19 August 2019}

\section{References}

1. Semah F, Picot MC, Adam C, Broglin D, Arzimanoglou A, Bazin B, et al. Is the underlying cause of epilepsy a major prognostic factor for recurrence? Neurology. 1998;51(5):1256-62

2. Blumcke I, Thom M, Aronica E, Armstrong DD, Bartolomei F, Bernasconi A, et al. International consensus classification of hippocampal sclerosis in temporal lobe epilepsy: a Task Force report from the ILAE Commission on Diagnostic Methods. Epilepsia. 2013;54(7):1315-29.

3. Dube CM, Brewster AL, Baram TZ. Febrile seizures: mechanisms and relationship to epilepsy. Brain Dev. 2009;31(5):366-71.

4. Dube C, Richichi C, Bender RA, Chung G, Litt B, Baram TZ. Temporal lobe epilepsy after experimental prolonged febrile seizures: prospective analysis. Brain. 2006;129(Pt 4):911-922.

5. Feng B, Chen Z. Generation of febrile seizures and subsequent epileptogenesis. Neurosci Bull. 2016;32(5):481-92.

6. Lubin FD. Epileptogenesis: can the science of epigenetics give us answers? Epilepsy Curr. 2012;12(3):105-10.

7. Mehler MF. Epigenetic principles and mechanisms underlying nervous system functions in health and disease. Prog Neurobiol. 2008;86(4):305-41.

8. Guo JU, Ma DK, Mo H, Ball MP, Jang MH, Bonaguidi MA, et al. Neuronal activity modifies the DNA methylation landscape in the adult brain. Nat Neurosci. 2011;14(10):1345-51.

9. Robertson KD. DNA methylation and human disease. Nat Rev Genet. 2005;6(8): 597-610.

10. Tahiliani M, Koh KP, Shen Y, Pastor WA, Bandukwala H, Brudno Y, et al. Conversion of 5-methylcytosine to 5-hydroxymethylcytosine in mammalian DNA by MLL partner TET1. Science. 2009;324(5929):930-5.

11. Iurlaro M, Ficz G, Oxley D, Raiber EA, Bachman M, Booth MJ, et al. A screen for hydroxymethylcytosine and formylcytosine binding proteins suggests functions in transcription and chromatin regulation. Genome Biol. 2013; 14(10):R119.

12. Khare T, Pai S, Koncevicius K, Pal M, Kriukiene E, Liutkeviciute Z, et al. 5-hmC in the brain is abundant in synaptic genes and shows differences at the exon-intron boundary. Nat Struct Mol Biol. 2012:19(10):1037-43.

13. Duymich CE, Charlet J, Yang X, Jones PA, Liang G. DNMT3B isoforms without catalytic activity stimulate gene body methylation as accessory proteins in somatic cells. Nat Commun. 2016;7:11453.

14. Hsu DW, Lin MJ, Lee TL, Wen SC, Chen X, Shen CK. Two major forms of DNA (cytosine-5) methyltransferase in human somatic tissues. Proc Natl Acad Sci U S A. 1999;96(17):9751-6.

15. Chen T, Ueda $Y$, Xie S, Li E. A novel Dnmt3a isoform produced from an alternative promoter localizes to euchromatin and its expression correlates with active de novo methylation. J Biol Chem. 2002;277(41):38746-54

16. Li E, Bestor $\mathrm{TH}$, Jaenisch R. Targeted mutation of the DNA methyltransferase gene results in embryonic lethality. Cell. 1992;69(6):915-26.

17. Okano M, Bell DW, Haber DA, Li E. DNA methyltransferases Dnmt3a and Dnmt3b are essential for de novo methylation and mammalian development. Cell. 1999;99(3):247-57.

18. Chedin F. The DNMT3 family of mammalian de novo DNA methyltransferases. Prog Mol Biol Transl Sci. 2011;101:255-85.

19. Feng J, Chang H, Li E, Fan G. Dynamic expression of de novo DNA methyltransferases Dnmt3a and Dnmt3b in the central nervous system. J Neurosci Res. 2005;79(6):734-46.

20. Watanabe D, Uchiyama K, Hanaoka K. Transition of mouse de novo methyltransferases expression from Dnmt3b to Dnmt3a during neural progenitor cell development. Neuroscience. 2006;142(3):727-37.

21. Lister R, Mukamel EA, Nery JR, Urich M, Puddifoot CA, Johnson ND, et al. Global epigenomic reconfiguration during mammalian brain development. Science. 2013;341(6146):1237905

22. Simmons RK, Stringfellow SA, Glover ME, Wagle AA, Clinton SM. DNA methylation markers in the postnatal developing rat brain. Brain Res. 2013; 1533:26-36.

23. Kadriu B, Guidotti A, Chen Y, Grayson DR. DNA methyltransferases1 (DNMT1) and 3a (DNMT3a) colocalize with GAD67-positive neurons in the GAD67GFP mouse brain. J Comp Neurol. 2012:520(9):1951-64.

24. Feng J, Zhou Y, Campbell SL, Le T, Li E, Sweatt JD, et al. Dnmt1 and Dnmt3a maintain DNA methylation and regulate synaptic function in adult forebrain neurons. Nat Neurosci. 2010;13(4):423-30.
25. Morris MJ, Adachi M, Na ES, Monteggia LM. Selective role for DNMT3a in learning and memory. Neurobiol Learn Mem. 2014;115:30-7.

26. Morris MJ, Na ES, Autry AE, Monteggia LM. Impact of DNMT1 and DNMT3a forebrain knockout on depressive- and anxiety like behavior in mice. Neurobiol Learn Mem. 2016;135:139-45.

27. Oliveira AM, Hemstedt TJ, Bading $H$. Rescue of aging-associated decline in Dnmt3a2 expression restores cognitive abilities. Nat Neurosci. 2012; 15(8):1111-3.

28. Oliveira AM, Hemstedt TJ, Freitag HE, Bading H. Dnmt3a2: a hub for enhancing cognitive functions. Mol Psychiatry. 2016;21(8):1130-6.

29. Miller-Delaney SF, Das S, Sano T, Jimenez-Mateos EM, Bryan K, Buckley PG, et al. Differential DNA methylation patterns define status epilepticus and epileptic tolerance. J Neurosci. 2012;32(5):1577-88.

30. Kobow K, Kaspi A, Harikrishnan KN, Kiese K, Ziemann M, Khurana I, et al. Deep sequencing reveals increased DNA methylation in chronic rat epilepsy. Acta Neuropathol. 2013;126(5):741-56.

31. Ryley Parrish R, Albertson AJ, Buckingham SC, Hablitz JJ, Mascia KL, Davis Haselden W, et al. Status epilepticus triggers early and late alterations in brain-derived neurotrophic factor and NMDA glutamate receptor Grin2b DNA methylation levels in the hippocampus. Neuroscience. 2013;248C:602-19.

32. Miller-Delaney SF, Bryan K, Das S, McKiernan RC, Bray IM, Reynolds JP, et al. Differential DNA methylation profiles of coding and non-coding genes define hippocampal sclerosis in human temporal lobe epilepsy. Brain. 2015;138(Pt 3):616-631.

33. Williams-Karnesky RL, Sandau US, Lusardi TA, Lytle NK, Farrell JM, Pritchard EM, et al. Epigenetic changes induced by adenosine augmentation therapy prevent epileptogenesis. J Clin Invest. 2013; 123(8):3552-63.

34. Kobow K, Jeske I, Hildebrandt M, Hauke J, Hahnen E, Buslei R, et al. Increased reelin promoter methylation is associated with granule cell dispersion in human temporal lobe epilepsy. J Neuropathol Exp Neurol. 2009;68(4):356-64

35. Zhu Q, Wang L, Zhang Y, Zhao FH, Luo J, Xiao Z, et al. Increased expression of DNA methyltransferase 1 and $3 a$ in human temporal lobe epilepsy. J Mol Neurosci. 2012;46(2):420-6.

36. He Q, Kim H, Huang R, Lu W, Tang M, Shi F, et al. The Daxx/Atrx complex protects tandem repetitive elements during DNA hypomethylation by promoting H3K9 trimethylation. Cell Stem Cell. 2015;17(3):273-86

37. Challen GA, Sun D, Jeong M, Luo M, Jelinek J, Berg JS, et al. Dnmt3a is essential for hematopoietic stem cell differentiation. Nat Genet. 2011;44(1):23-31.

38. Wu D, Feng B, Dai $Y$, Wu $X$, Chen B, Xu C, et al. Intergenerational transmission of enhanced seizure susceptibility after febrile seizures. EBioMedicine. 2017:17:206-15.

39. Debski KJ, Pitkanen A, Puhakka N, Bot AM, Khurana I, Harikrishnan KN, et al. Etiology matters - genomic DNA methylation patterns in three rat models of acquired epilepsy. Sci Rep. 2016;6:25668.

40. Wang L, Fu X, Peng X, Xiao Z, Li Z, Chen G, et al. DNA methylation profiling reveals correlation of differential methylation patterns with gene expression in human epilepsy. J Mol Neurosci. 2016:59(1):68-77.

41. Miller CA, Sweatt JD. Covalent modification of DNA regulates memory formation. Neuron. 2007:53(6):857-69.

42. LaPlant Q, Vialou V, Covington HE 3rd, Dumitriu D, Feng J, Warren BL, et al. Dnmt3a regulates emotional behavior and spine plasticity in the nucleus accumbens. Nat Neurosci. 2010;13(9):1137-43.

43. Lemmens EM, Lubbers T, Schijns OE, Beuls EA, Hoogland G. Gender differences in febrile seizure-induced proliferation and survival in the rat dentate gyrus. Epilepsia. 2005;46(10):1603-12.

44. Crespel A, Rigau V, Coubes P, Rousset MC, de Bock F, Okano H, et al. Increased number of neural progenitors in human temporal lobe epilepsy. Neurobiol Dis. 2005;19(3):436-50

45. Xiong $Y$, Zhou $H$, Zhang L. Influences of hyperthermia-induced seizures on learning, memory and phosphorylative state of CaMKllalpha in rat hippocampus. Brain Res. 2014;1557:190-200

46. Martinos MM, Yoong M, Patil S, Chin RF, Neville BG, Scott RC, et al. Recognition memory is impaired in children after prolonged febrile seizures. Brain. 2012:135(Pt 10):3153-3164.

47. Wu H, Coskun V, Tao J, Xie W, Ge W, Yoshikawa K, et al. Dnmt3a-dependent nonpromoter DNA methylation facilitates transcription of neurogenic genes. Science. 2010;329(5990):444-8. 
48. Wu Z, Huang K, Yu J, Le T, Namihira M, Liu Y, et al. Dnmt3a regulates both proliferation and differentiation of mouse neural stem cells. J Neurosci Res. 2012;90(10):1883-91.

49. Miller CA, Gavin CF, White JA, Parrish RR, Honasoge A, Yancey CR, et al. Cortical DNA methylation maintains remote memory. Nat Neurosci. 2010; 13(6):664-6.

50. Jarmasz JS, Stirton H, Davie JR, Del Bigio MR. DNA methylation and histone post-translational modification stability in post-mortem brain tissue. Clin Epigenetics. 2019;11(1):5.

51. Navarrete-Modesto V, Orozco-Suarez S, Feria-Romero IA, Rocha L. The molecular hallmarks of epigenetic effects mediated by antiepileptic drugs. Epilepsy Res. 2019;149:53-65

52. Schijns O, Karaca U, Andrade P, de Nijs L, Kusters B, Peeters A, et al. Hippocampal GABA transporter distribution in patients with temporal lobe epilepsy and hippocampal sclerosis. J Chem Neuroanat. 2015;68:39-44.

53. Wierschke S, Gigout S, Horn P, Lehmann TN, Dehnicke C, Brauer AU, et al. Evaluating reference genes to normalize gene expression in human epileptogenic brain tissues. Biochem Biophys Res Commun. 2010;403(34):385-90.

54. Faul F, Erdfelder E, Lang AG, Buchner A. G*Power 3: a flexible statistical power analysis program for the social, behavioral, and biomedical sciences. Behav Res Methods. 2007;39(2):175-91.

\section{Publisher's Note}

Springer Nature remains neutral with regard to jurisdictional claims in published maps and institutional affiliations.

Ready to submit your research? Choose BMC and benefit from:

- fast, convenient online submission

- thorough peer review by experienced researchers in your field

- rapid publication on acceptance

- support for research data, including large and complex data types

- gold Open Access which fosters wider collaboration and increased citations

- maximum visibility for your research: over $100 \mathrm{M}$ website views per year

At BMC, research is always in progress.

Learn more biomedcentral.com/submissions 